\title{
A escrita sob o olhar do aluno no Ensino Médio: representações e reflexões
}

\author{
The writing under the student's look at middle school: representations and reflections
}

\author{
Dalve Oliveira Batista-Santos* \\ Universidade Federal do Tocantins \\ Pontifícia Universidade Católica de São Paulo \\ Palmas, Tocantins, Brasil
}

Dimas Henrique Pereira de Oliveira Silva**

Universidade Federal do Tocantins

Porto Nacional, Tocantins, Brasil

\begin{abstract}
Resumo: A prática de escrita no Ensino Médio (EM) é temática de muitas pesquisas (KLEIMAN, 2007) que se preocupam com o processo de ensino e aprendizagem dessa tecnologia. Essas pesquisas elucubram a relevância de uma visão reflexiva e crítica para o ambiente escolar. Batista-Santos (2017) constatou que a falta da proficiência escritora dos ingressantes no Ensino Superior (ES) se dá pela forma com que as capacidades escritoras são trabalhadas e desenvolvidas no EM. Nesse contexto, a pesquisa é de cunho qualitativointerpretativista e se insere na área da Linguística Aplicada que, baseada nos Novos Estudos do Letramento (LEA e STREET, 1995, 2010, 2012; KLEIMAN 1995, 2007; SOARES, 2009) e pesquisadores da área de escrita (DOLZ e SCHNEUWLY, 2010; FIAD, 2011, 2015; BATISTA-SANTOS, 2017; dentre outros), busca investigar as representações de alunos do EM acerca de suas competências escritoras, levando em consideração o seu ingresso no Ensino Superior (ES). Para tanto, utilizamos a entrevista semiestruturada por ser uma técnica introspectiva, composta por questões discursivas e aplicadas aos alunos da rede estadual de ensino, no município de Palmas, no estado do Tocantins. Destarte, acreditamos que o estudo será relevante por possibilitar importantes reflexões a respeito das práticas de escrita utilizadas por alunos no EM. Além disso, esta pesquisa contribuirá para a identificação de possíveis problemas que permeiam o sistema educacional de ensino, no que se refere ao processo de ensino e aprendizagem da escrita.
\end{abstract}

Palavras-chave: Escrita. Ensino Médio. Lentamente.

\begin{abstract}
Writing Practices at High School (HS) has been a theme for many research interests (KLEIMAN, 2007) concerned with both teaching and learning processes. Such interests cover the relevance of a reflexive and critical perspective within school environment. In their research, Batista-Santos (2017) verified that the lack of written proficiency in College arrivals stems from the way in which written skills are developed and worked during High School. In this context, this qualitative-interpretative research is inserted in the Applied Linguistics field - that based on New Literacy Studies (LEA e STREET, 1995, 2010, 2012; KLEIMAN 1995, 2007; SOARES, 2009) as well as in written skills researchers results (DOLZ e SCHNEUWLY, 2010; FIAD, 2011, 2015; BATISTA-SANTOS, 2017; among others) - aims to investigate High School students' representations about their own written competences, taking into account their High Education entrance. To
\end{abstract}

* Doutoranda e mestra em Linguística Aplicada e Estudos da Linguagem pela Pontifícia Universidade Católica de São Paulo (PUC-SP). Professora Assistente II, da Universidade Federal do Tocantins - UFT, lotada no curso de Letras - Língua Portuguesa e Respectivas Literaturas. Email: dalve@uft.edu.br.

** Graduando em Letras - Língua Portuguesa e Respectivas Literaturas pela Universidade Federal do Tocantins - UFT, Campus de Porto Nacional-TO. Email: ruymartinsbatista@gmail.com. 
achieve our results we gave preference to semi-structured interviews for its introspective technic. The survey was composed by open-ended questions applied to state High School students based in Palmas, Tocantins. We believe this study (research) is relevant to academics because it creates possibilities for important reflections toward written practices used by High School students. Besides, it will contribute to identify possible problems permeating Brazilian educational system in relation to teaching and learning processes in developing writing skills.

Keywords: Writing. High School. Literacy.

\section{PALAVRAS INICIAIS...}

O ambiente escolar nem sempre é estimulante para o desenvolvimento de competências que abrangem a apropriação da leitura e a escrita. Uma vez que essas competências não são prioridades no ensino da Língua Portuguesa (LP), que prioriza ensinar literatura, fundamentos da linguística e gramática tradicional (KLEIMAN, CENICEROS e TINOCO, 2013.p.73).

Essa problemática já permeia há certo tempo algumas pesquisas (CASTRO, 2009; FIAD, 2011) e, recentemente, Batista-Santos (2017) constatou que grande parte das dificuldades que os novos ingressantes no Ensino superior (ES) sentem em relação à escrita é decorrente de uma má formação no Ensino Médio (EM). Visando contribuir com soluções para essa temática, o presente estudo tem por objetivo dar voz aos alunos do EM para que, por meio de suas reflexões e representações, possam ser identificados possíveis problemas que colaboram para o fracasso no processo de ensino e aprendizagem da escrita, em nosso sistema de ensino.

Para tanto, a pesquisa insere-se na área da Linguística Aplicada e adotou metodologia de natureza qualitativa (MOITA LOPES, 2006), para que, por meio do instrumento introspectivo, o diário reflexivo, os alunos do EM de uma escola pública estadual, no município de Palmas, estado do Tocantins, transcrevessem suas concepções acerca da escrita no decorrer de suas vidas. A escolha do diário como instrumento de coleta de dados deve-se ao fato de esse gênero textual ter como princípio básico oportunizar aos sujeitos a reflexão sobre suas maneiras de aprender determinado conteúdo.

Importa dizermos que o diário reflexivo é compreendido, nesta pesquisa, como uma produção textual individualizada, consequência de reflexões feitas pelos sujeitos participantes, considerando sua subjetividade (ações e reações) acerca do tema solicitado, a escrita (LIBERALI, 1999). Além disso, o gênero diário reflexivo permite maior abertura e liberdade para aqueles que o escreve, pois nele os sujeitos poderão expressar-se de maneira espontânea, porém, organizada em torno de argumentos pessoais.

Diante disso, este artigo está dividido em três seções. Na primeira, apresentamos a perspectiva teórica que fundamenta a pesquisa. Já na segunda, trazemos algumas reflexões a respeito da escrita e sua relação com a competência leitora e os aspectos em que ambas se distanciam. E na terceira, evocamos as vozes dos entrevistados, que, por sua vez, dão sentido a todo o trabalho. 


\section{DO “NOVO TERMO”, CONCEPÇÕES A RESPEITO DO LETRAMENTO, AOS NOVOS ESTUDOS DO LETRAMENTO (NEL)}

A nomenclatura letramento, de acordo com Soares (2009), é recente entre as ciências linguísticas. Teve sua origem na palavra inglesa literacy, que, por sua vez, não corresponde ao termo já dicionarizado na língua portuguesa, significando o ato de escrever ou a aquisição da "tecnologia" escritora. Letramento, diante dessa perspectiva, é mais que o ato da aquisição de "novas tecnologias" (leitura e escrita), pois nos leva a compreendê-lo como a aquisição dessas interligadas à funcionalidade do indivíduo em um determinado contexto social.

Embora a expressão literacy já fosse dicionarizada pela língua inglesa desde o século XIX, o referido termo, com esta correspondência, adveio ao final dos anos 70 e início dos anos 80. Segundo Soares (2004), deu-se nos Estados Unidos, quando o National Assessment of Educational Progress (NAEP), depois de várias pesquisas, constatou que um grande quantitativo de jovens, após terem concluído o ensino básico, teriam encontrado diversas dificuldades ao lidarem com práticas que envolvessem a escrita em seus ambientes de trabalho.

Diante dessa realidade, foi necessário que esses indivíduos, que apresentavam dificuldades em lidar com práticas referentes à escrita e à leitura, fossem estudados e classificados de maneira diferente daqueles que não possuíam as tecnologias da leitura e da escrita. Foi aí que o termo literacy passou a ganhar outro significado, deixando de corresponder apenas aos capazes de lidar com as tecnologias das letras, englobando também aqueles que fazem o uso de práticas que pressupõe certo conhecimento das capacidades leitoras e escritoras, como é o caso dos exemplos citados abaixo por Soares (2009), se uma pessoa adulta é considerada analfabeta, porém está rodeada por ambientes que promovam a leitura e a escrita, ou se interessa por

[...] ouvir a leitura de jornais feita por um alfabetizado, [...] Da mesma forma, a criança que ainda não se alfabetizou, mas já folheia livros, finge lê-los, [...] essa criança é ainda "analfabeta", porque não aprendeu a ler e a escrever, mas já penetrou no mundo do letramento, já é de certa forma, letrada (SOARES, 2009, p.24).

Durante o período dessas descobertas, deu-se o que Soares (2004 p.5-6) chama de "Fenômeno cultural, geográfico e socioeconômico de novas práticas de leitura", pois, na mesma época em que surgiu o termo literacy nos Estados Unidos e na Inglaterra, nasceu em Portugal Literacia, letramento no Brasil e Iletrisme na França.

Em países desenvolvidos, mesmo no século XX, o índice de pessoas que não possuíam capacidade de ler e escrever (“analfabetos”) era baixíssimo, em contrapartida, o Brasil ainda possuía um grande quantitativo. Devido a esse quantitativo, o país se posicionou positivamente em relação aos novos acontecimentos, pois foi possível, desde 
a data dessas descobertas, ofertar uma nova forma metodológica ao processo de alfabetizar.

Essa significação, chamada de letramento, não se refere ao simples ato de aprender o sistema alfabético, mas sim o movimento da linguagem escrita, considerando o contexto sócio-histórico-cultural do "aluno, sua época, suas necessidades, as exigências da sociedade, os papéis que se esperam possa desempenhar, os novos instrumentos e tecnologias que se desejam que saiba usar" (KLEIMAN, 2010, p. 382). A partir da década de 80, surge os Novos Estudos de Letramento (NEL), traduzido do Inglês New Literacy Studies (NLS). De acordo Street (2013), os pesquisadores dos NEL consideraram de extrema importância dá uma nova ressignificação a esses estudos, pois o termo Letramento é essencialmente carregado de ideologias.

Desse modo, Street trouxe uma distinção entre a antiga definição de Letramento', a que ele chama de "modelo autônomo", e a definição que é defendida pelos NEL, denominada "modelo ideológico". O autor descreve o "modelo autônomo" da seguinte maneira:

\begin{abstract}
A perspectiva padrão em muitos campos, da escolarização a programas de desenvolvimento, trabalha com a suposição de que o letramento por si só - autonomamente - terá efeitos sobre outras práticas sociais e cognitivas. Introduzir o letramento para as crianças na escola, para pessoas 'iletradas' em vilarejos e para jovens pobres em áreas urbanas, entre outros, teria o efeito de intensificar suas habilidades cognitivas, melhorar suas perspectivas econômicas, torná-los cidadãos melhores, independentemente das condições sociais e econômicas que respondem pelo seu 'iletrismo', em primeiro lugar. Eu me refiro a isso como um modelo 'autônomo' de letramento (STREET, 2013, p. 53).
\end{abstract}

É por essa razão que, ao falar do modelo autônomo, Soares (2009, p.72) o define como versão "fraca" do letramento, justamente por acreditar que apenas o letramento por si mesmo é capaz de transformar realidades. Já a respeito do modelo ideológico, o qual Soares (2009, p.72) nomeia versão "Forte", Street descreve como uma perspectiva que contempla aspectos socioculturais nas práticas de letramento, pois tais práticas se alteram de um contexto para outro.

No modelo ideológico de letramento, diferentemente do modelo autônomo, o letramento é considerado uma prática social, e não apenas habilidades técnicas e neutras, que "[...] está sempre incrustado em princípios epistemológicos socialmente construídos" (STREET, 2013, p.53). Na concepção do modelo ideológico, as diversas maneiras que os sujeitos utilizam a leitura e a escrita estão relacionadas às representações de poder, conhecimento, identidade, ser. Está sempre relacionada às práticas sociais que envolvem as tecnologias: leitura e a escrita.

Diante desse conceito, não há cidadão considerado totalmente "iletrado", pois, muito embora existam pessoas não possuidoras das tecnologias das letras, em seus contextos de vida, de alguma forma, elas são direcionadas a exercer práticas que são anteriores ao ato da alfabetização, como: comprar, vender trocar, entre outras. 


\section{DO VELHO AO NOVO: ESTUDOS DE LETRAMENTO COM FOCO NA COMPETÊNCIA ESCRITORA}

Com o surgimento do "novo" termo letramento, um pensamento no meio educacional foi disseminado de maneira equivocada e sem respaldo teórico. Tal pensamento deve-se ao equívoco dicotômico da alfabetização - que é "a aquisição do sistema convencional de escrita, o aprender a ler como decodificação e a escrever como codificação" (SOARES, 2004. p.14) - e do letramento - que se refere ao "desenvolvimento de habilidades textuais de leitura e de escrita, o convívio com tipos e gêneros variados de textos e de portadores de textos, a compreensão das funções da escrita" (p.15).

Essa dissociação tem causado alguns problemas, como apontam Soares (2004) e Kleiman (2010), pois, de acordo com autoras, nas últimas duas décadas os índices de avaliações $\left(\mathrm{SAEB}^{1}\right.$; $\left.\mathrm{PISA}^{2}\right)$ internos, estaduais, nacionais e internacionais apontam grandes quedas no que se refere ao nível de proficiência das capacidades leitoras e escritoras dos alunos do ensino básico, especificamente do ensino fundamental, o que é reflexo de um processo de alfabetização não significativo.

Soares (2004), em seu texto Letramento e alfabetização: as muitas facetas, propõe uma seção denominada: "A desinvenção da alfabetização", apontando para essa problemática, pois os índices de avaliações também dizem que grande parte dos alunos saem do ensino fundamental não alfabetizados, porém letrados. E, ao final da seção, a autora propõe a necessidade de deixarmos claro que apoiar a especificação do processo de alfabetizar não remete ao simples fato de dissociá-lo do letramento. Porém, de forma lamentável, nos dias atuais surge um discurso equivocado "[...] de que, se as crianças estão sendo, de certa forma, letradas na escola, não estão sendo alfabetizadas, parece estar conduzindo à solução de um retorno à alfabetização como processo autônomo, independente do letramento e anterior a ele" (SOARES, 2004. p.11).

Esses posicionamentos geraram o que Kleiman (2010) chama de "Falsa dicotomia", que é justamente colocar em posições opostas o ato de alfabetizar e as práticas e eventos de letramento. Assim, segundo a autora, essa falsa dicotomia gira em torno das

\footnotetext{
${ }^{1}$ O Sistema de Avaliação da Educação Básica - Saeb, instituído em 1990, é composto por um conjunto de avaliações externas em larga escala e tem como principal objetivo realizar um diagnóstico da educação básica brasileira e de alguns fatores que possam interferir no desempenho do estudante, fornecendo um indicativo sobre a qualidade do ensino ofertado. O levantamento produz informações que subsidiam a formulação, reformulação e o monitoramento das políticas públicas nas esferas municipal, estadual e federal, visando a contribuir para a melhoria da qualidade, equidade e eficiência do ensino. Além disso, procura também oferecer dados e indicadores sobre fatores de influência do desempenho dos alunos nas áreas e anos avaliados. (http://portal.inep.gov.br/educacao-basica/saeb).

${ }^{2}$ Programme for International Student Assessment. O PISA é uma grande avaliação internacional à literacia dos alunos de 15 anos, em três áreas-chave: Ciências, Matemática e Leitura. Cada leva de testes privilegia uma área em particular. (https://www.publico.pt/2013/12/04/sociedade/noticia/o-que-e-o-pisa-quem-opaga-1614920).
} 
concepções de que "ou a criança é alfabetizada pelo método tradicional de alfabetização ou ela é letrada pelo 'novo método' do letramento" (p.378).

Kleiman (2010) ratifica a importância da relação dialógica e complementar entre os dois processos, alfabetizar e letrar. Sobre isso, a autora assevera que tanto o processo de alfabetização quanto o processo de letramento se utilizam de estratégias sócio-históricoculturais situadas, para possibilitar de maneira significativa a apropriação da escrita. Segundo a referida autora,

\begin{abstract}
Ora, reitero (cf. KLEIMAN, 2005) que não existe 'método' de letramento, como conjunto de estratégias didáticas para o ensino inicial da leitura e da escritura. Há muitos modos métodos, se forem sistemáticos - de alfabetizar, e todos eles, simples ou complicados, modernos ou antigos, penosos ou prazerosos, fazem parte do conjunto de práticas escolares de letramento e são sócio-histórica e culturalmente situados. A alfabetização é uma prática de letramento que pode envolver diferentes estratégias (reconhecimento global da palavra, reconhecimento de sílabas, leitura em voz alta, leitura silenciosa), diversos gêneros (cartilhas, exercícios, imagens, notícias, relatos, contos, verbetes, famílias de palavras), diferentes tecnologias (lápis, caneta, papel, quadro negro, giz, lousa branca, pincel atômico, livro, tela e teclado) (KLEIMAN, 2010. p.378,379).
\end{abstract}

Nessa linha de pensamento, o ato de alfabetizar está interligado ao do letramento, pois como apresentado por Kleiman (2010), o processo de alfabetizar os sujeitos é uma prática de letramento que engloba diversas formas ou estratégias. Trabalhos como o de Assolini e Tfouni (1999) evidenciam algumas dessas noções equivocadas a respeito da alfabetização e letramento. Como podemos ver nos exemplos abaixo,

Os alunos desta classe são iletrados, precisam ser alfabetizados com urgência"; "A coordenadora pedagógica disse que o mais importante é que a criança, não precisa saber tabuada, mas precisa saber ler corretamente"; "O letramento é a salvação da lavoura, porque se o aluno for letrado ele saberá interpretar um texto; vai escrever muito vai entender matemática, ciências, tudo etc. [...] (ASSOLINI e TFOUNI. 1999. p. 25). (Grifo nosso)

Uma característica dos NEL é criticar e erradicar comentários como esses, pois, ao nascer, a criança é inserida em contextos que evidenciam práticas de letramento. $\mathrm{O}$ resultado disso é que, antes das crianças obterem contatos com a alfabetização, provavelmente já terão um certo engajamento com as práticas de letramento, que não se restringem ao simples ato codificar e decodificar. Em outras palavras, os estudos do letramento defendem "uma concepção pluralista e multicultural das práticas de uso da língua escrita” (KLEIMAN, 2008, p.490).

Destarte, o letramento e a alfabetização têm que ser trabalhados em conjunto, é o que Soares (2004), de forma metafórica, chama de pêndulo, pois um pêndulo não se posiciona de maneira rígida em apenas um local, antes se mobiliza e perpassa por todas as extremidades possíveis. 
O ato de exercer comunicação por meio da escrita não é uma tarefa fácil, e sim laboriosa e complexa. Como afirma Marcuschi (2010, p.65),

Pressupõe um sujeito não apenas atento às exigências, às necessidades e aos propósitos requeridos por seu contexto sócio-histórico e cultural, mas também capaz de realizar diversas ações e projeções de natureza textual, discursiva e cognitiva, antes e no decorrer da elaboração textual.

E como esse processo se inicia na infância, exige-se então que uma criança seja capaz de representar a linguagem, que é um fenômeno físico, por um sistema constituído por sinais gráficos que são totalmente abstratos. Para que esse processo ocorra com sucesso, Kleiman (2007), fazendo referência aos Parâmetros Curriculares Nacionais (1997), descreve-o da seguinte maneira:

\footnotetext{
Para poder ler e escrever, o aluno precisa reconhecer e usar componentes relativos ao domínio do código, como a segmentação em palavras e frases, as correspondências regulares de som-letra, as regras ortográficas, o uso de maiúsculas, assim como componentes relativos ao domínio textual, tais como o conjunto de recursos coesivos de conexão, de relação temporal, de relação causal. Nada disso seria relevante se o aluno não conseguisse também atribuir sentidos aos textos que lê e escreve segundo os parâmetros da situação comunicativa (KLEIMAN, 2007, p.06).
}

Essa forma abstrata contida nos sistemas gráficos tem que, de alguma forma, ganhar aspectos físicos, palpáveis, reais, com a realidade contextual em que o aluno está inserido, para que, assim, ele possa fazer o uso dessas competências. Mediante isso, "a concepção da escrita dos estudos de letramento pressupõe que as pessoas e os grupos sociais são heterogêneos e que as diversas atividades entre as pessoas acontecem de modos muito variados" (KLEIMAN, 2007, p.15). Essa variedade abrange, como podemos ver a seguir nas definições de Soares (2009) acerca das competências leitoras e escritoras diante da perspectiva dos NEL.

A competência escritora, na perspectiva dos Novos Estudos de Letramento, demonstra uma significativa contribuição para as pesquisas da área. Tal perspectiva de estudo, de acordo com Batista-Santos (2017, p.97), surgiu de pesquisas realizadas por Lea e Street em "duas instituições de Ensino Superior, no Reino Unido". Os resultados dessas pesquisas apontaram lacunas no processo de aprendizagem, referentes às instruções necessárias para as formulações dos textos, tanto da parte dos discentes quanto dos docentes.

Ainda na perspectiva Batista-Santos (2017), tais lacunas permitiram uma reflexão acerca da escrita em diversos ambientes institucionais, pois, segundo Street (2010), as produções escritas forneceram "indícios, não no nível de habilidades técnicas, da superfície da competência linguística [...] mas no nível da epistemologia, da autoridade e da contestação do conhecimento" (STREET, 2010, p.545). 
Doravante, de acordo com Street (2014, p.479-480), a escrita, na perspectiva dos NEL, é compreendida por meio de três modelos ou perspectivas. O primeiro é denominado de modelo de habilidades de estudo, o qual vê a escrita inteiramente como um fenômeno mental e cognitivo. Nele, o aluno não tem dificuldades nas transições de níveis de ensino, transferindo assim seus conhecimentos de um ambiente de estudos para outro. As preocupações atingidas neste modelo são classificadas por Street (2014) como superficiais, pois se pautam em "aspectos formais da língua" (p.480).

O segundo modelo é denominado modelo de socializaçãa acadêmica, o qual prevê que os gêneros acadêmicos em geral possuem uma estrutura estável e, ao associar tais estruturas, os alunos não teriam problema algum ao reproduzi-los. Já o modelo de letramentos acadêmicos faz o uso tanto do modelo de habilidades de estudo quanto do modelo de socialização acadêmica. Todavia, este, em suas concepções, vai muito além das concepções dos modelos anteriores, pois, no primeiro, as responsabilidades são atribuídas aos alunos, no segundo, aos professores e, no terceiro, são levados em conta os alunos, professores, instituições e os contextos onde esses se encontram.

\section{ANÁLISE E DISCUSSÃO DOS DADOS: A ESCRITA SOB O OLHAR DO ALUNO NO ENSINO MÉDIO}

Após ter discutido a perspectiva teórica que embasa esta pesquisa, discutiremos neste momento as representações que foram coletadas dos alunos. O corpus do presente artigo foi composto por diários reflexivos. Para a produção desse gênero, foi solicitado aos alunos que narrassem a história de suas impressões e contatos com o desenvolvimento da competência escritora, desde o Ensino Fundamental até o EM.

Os diários foram realizados por 25 alunos do terceiro ano "D" do EM, período noturno, de uma escola pública estadual, na cidade de Palmas, capital do Tocantins. Porém, apenas 13 diários contemplavam o que propunha o objetivo da pesquisa. A escolha da referida turma foi decorrente do interesse dos alunos em se inscreverem no ENEM. Assim, por motivo de sigilo, o nome da instituição visitada para a realização da pesquisa e os nomes dos alunos que participaram não serão revelados, visto que fizemos a análise apenas de seus relatos.

Sendo assim, para a diferenciação entre os textos, os participantes estão representados como D1 (diário um), D2 (diário dois), D3 (diário três), D4 (diário quatro), D5 (diário cinco), D6 (diário seis), D7 (diário sete), D8 (diário oito), D9 (diário nove), D10 (diário dez), D11 (diário onze), D12 (diário doze) e D13 (diário treze). Destacamos em negrito e itálico os trechos relevantes para nossa análise.

Vale ressaltar que as partes dos textos produzidos pelos alunos foram transcritas literalmente da forma expressa por eles. As representações estão seccionadas da seguinte maneira: a primeira subseção, Ensino Fundamental, descreve como ocorreu o processo de desenvolvimento da capacidade escritora dos alunos desde a alfabetização ao término do Ensino Fundamental II (EFII). 
A segunda subseção, Ensino Médio, traz a forma como foi trabalhada a capacidade escritora dos alunos nos três últimos anos de estudos. E a última, Preparação para o ingresso no ES, evocará a opinião dos alunos a respeito do ENEM e outros processos seletivos cujos exames farão para o ingresso na Universidade e ainda demonstra se eles se sentem preparados para lidar com os gêneros que permeiam o ambiente acadêmico.

\subsection{Representações do Ensino Fundamental II}

Os relatos fornecidos pelos alunos na presente pesquisa nem sempre fazem parte dos nove anos do EF. Muitos deles se encaixariam nos anos predecessores do Ensino Fundamental, visto que grande parte das crianças têm seus primeiros contatos com a tecnologia das letras muito antes do Ensino Fundamental II (KLEIMAN, 2013). E, para uma melhor compreensão do leitor, destacamos em negrito as partes que correspondem a esse primeiro contato dos alunos com a escrita. Dessa forma, seguimos, pois, aos relatos:

D1: Aprender e entender os conceitos para fazer um bom texto; ainda estou conhecendo. No fundamental não há aulas voltadas para isto especificamente; aprendi vários temas nas aulas de português, mas nada que me prepara-se para a redação do ENEM.

D2: desde muito pequenos trabalhamos a escrita as formas corretas como se deve escrever os acentos que cada palavra compõe e no decorrer de tudo aprendemos corretamente como se deve seguir uma escrita padrão.

Os relatos do primeiro diário iniciam com o autor atribuindo o desenvolvimento de sua capacidade escritora a habilidades cognitivas "aprender e entender". Todavia, ao afirmar que "No fundamental não há aulas voltadas para isto especificamente" (D1), esse estudante também tem consciência de que poderia ter conseguido uma maior proficiência se seu contexto de ensino fosse mais significativo para sua aprendizagem.

$\mathrm{Na}$ representação de D2, percebemos marcas do modelo de letramento autônomo, visto que este resume a escrita apenas a aspectos estruturais e superficiais da língua (" $n o$ decorrer de tudo (educação básica) aprendemos corretamente como se deve seguir uma escrita padrão", D2). Esse relato demonstra uma oposição ao que é defendido pelos NEL em relação ao desenvolvimento da competência escritora nas escolas. Pois a educação básica não deveria apenas 'seguir rigorosamente uma escrita padrão', mas sim oferecer ao aluno:

A oportunidade de entender as situações sociais de interação que têm o texto escrito como parte constitutiva e as significações que essa interação tem para a comunidade local e que pode ter para outras comunidades. Em suma, significa ensinar o aluno a usar a escrita em situações do cotidiano como cidadão crítico (TERZI, 2006, p. 05). 
Dessa forma, é de suma importância que os alunos, ao passarem tempo nas agências de letramento, despertem o interesse pelo uso social das competências leitoras e escritoras, como evidenciam os próximos diários:

D3: Meu ensino fundamental foi simples e fácil, não tive problemas nem dificuldade em relação a caligrafia, foi um tempo bom, onde tudo era fácil.

D4: Desde pequena sempre fui interessada pela escrita. Começou tudo em casa e depois passei por ensino fundamental e assim aprimorei meus conhecimentos e a escrita, entretanto para mim a escrita é uma arte, pois escrevo de várias formas, letras totalmente diferentes umas das outras.

D5: Minha escrita iniciou-se a partir de traços feitos por mim de pequena, passei a usar livros de caligrafia para o aperfeiçoamento da minha letra.

D6: A minha escrita quase não foi trabalhada no ensino fundamental, nunca tive o hábito de escrever por conta própria e por conta disso tive muitos problemas na escrita quando percebi que precisava melhorá-la para o ENEM.

Ao analisarmos o trecho de $\mathrm{D} 4$, vemos um autor que, muito embora tenha "interesses" em escrever, assumindo assim as devidas responsabilidades relacionadas à escrita em interação com a sociedade, descreve que, ao passar pelo Ensino Fundamental, conseguiu 'aprimorar' seus conhecimentos e escrita (e assim aprimorei meus conbecimentos e a escrita, D4). Todavia, seu relato posteriormente contém uma conjunção adversativa, "entretanto", o que antecipa as ideias do autor, que se posiciona de maneira adversa à forma como são trabalhadas as tecnologias das letras em instituições responsáveis por agenciar o letramento.

D4 entende a escrita como uma arte, o que nos leva a subentender que a forma como se trabalham as competências escritoras nas escolas não são atraentes e aprazíveis, e, por mais que os alunos venham a se "aprimorar", como foi o caso da depoente, esses não veem prazer em tais atividades.

Já o relato do D3 e D5, por mais que se inicie com a mesma temática que o D4 (o interesse particular dos alunos pela escrita), pauta essa competência em apenas aspectos estruturais, dialogando assim com o modelo de habilidades de estudos, que, segundo Street, "[...] se ocupa principalmente dos aspectos superficiais do texto" (STREET. 2010, p.545). Diferentemente, a D6 em seu contexto não foram conferidas oportunidades para desenvolver a competência escritora, ao que esse, quando percebeu a importância da escrita, foi porque ela lhe foi exigida nos exames admissionais do ensino superior. $\mathrm{Na}$ representação de D6 notamos uma oposição ao que defende Kleiman (2007), pois, para a referida autora, "é na escola, agência de letramento por excelência de nossa sociedade, que devem ser criados espaços para experimentar formas de participação nas práticas sociais letradas [...]" (p. 04).

Ora, é perceptível um distanciamento de tais relatos com o modelo de Letramento Acadêmico, que visa estabelecer relações de "identidade, poder e 
autoridade" (STREET 2010, p.545), não apenas possibilitando aos educandos "oportunidade para passar no ENEM", mas sim fazendo da escrita de fato uma prática social.

\subsection{Representações e reflexões sobre o Ensino Médio}

Nesta subseção, apresentamos as reflexões dos alunos acerca do processo de escrita no EM, como será demonstrado a seguir.

D3: [...] Já o ensino médio tive várias dificuldades, nesses 3 anos não foi muito fácil, matérias acumuladas, trabalhos e provas, mas tudo normal. No ensino médio é onde se trabalha bastante a escrita, textos, redações e tudo mais, [...].

D7: No ensino médio, já obtive algumas dificuldades pelo fato de cada vez mais necessitar de uma melhor preparação e infelizmente o ensino foi falho e eu não obtive esse suporte.

Como podemos observar, os relatos anteriores indicam certa dificuldade dos alunos ao fazerem a transição do EFII para o EM. E essa dificuldade é previsível, por serem, de certa forma, ambientes distintos. Algumas pesquisas já vêm evidenciando esses processos de mudanças (BATISTA-SANTOS 2017, FIAD 2011). Porém, o diálogo estabelecido pelo modelo de socialização acadêmica infere que "[...]os discursos disciplinares e os gêneros são relativamente estáveis e que, tendo os estudantes dominado e entendido as regras básicas de um discurso acadêmico particular, estariam aptos a reproduzi-lo sem problemas" (STREET 2014, p.479).

Com isso, partindo do ponto de vista desse modelo, podemos ver o aluno do D3 achar "normal" as dificuldades apresentadas por esses contatos primários, pois, no modelo da socialização acadêmica, o aluno não teria maiores problemas ao assimilar as regras básicas ali pedidas, já que o professor seria o mediador no processo de aprendizagem. O que não vem a acontecer com o segundo relato desta seção, encontrado no D7. Esse, por sua vez, indica várias dificuldades nesse processo. E uma das dificuldades identificadas por ele é a falta de uma preparação para essa transição, principalmente no que se refere à produção textual. Tais relatos dialogam com as representações dos alunos na pesquisa de Batista-Santos (2017), segundo eles, se dão devido uma formação ineficiente para o desenvolvimento dessas capacidades, como podemos ver abaixo:

[...] Antes de ingressar na universidade não tinha uma exigência tão grande nas questões de escrita [...]. Na minha vida escolar escrevi muito pouco, quase nada [...]. O meu processo de escrita pode-se dizer que não foi um letramento rico em aprendizagem [...] me deparei com 
exigências que nunca havia tido nos meus ensinos anteriores (BATISTA-SANTOS. 2017, p.102).

Os relatos da pesquisa de Batista-Santos (2017) evidenciaram que essas práticas de letramentos, oriundas do ambiente escolar, afastam-se ao invés de ir ao encontro do modelo de letramentos acadêmicos, visto que esse tão somente vê a escrita como uma prática social, considerando o contexto dos educandos nesse processo. Isso implica que sejam dadas aos educandos todas as oportunidades possíveis, para que assim eles possam ter habilidade e proficiência no que se refere à competência escritora.

Considerando o objetivo do modelo de letramentos acadêmicos - em seu uso da escrita como prática social -, que é a "construção de sentidos, identidade, poder e autoridade" (STREET 2010, p.545), notamos em alguns relatos aspectos superficiais que vão de encontro a tal modelo, os quais podemos ver nos trechos a seguir:

D8: Já no ensino médio, o peso foi bem maior pois as matérias aumentam e a dificuldade vem junto. Agora no $3^{\circ}$ ano, procuro mais atenção, já que pretendo passar em odontologia.

D9: No ensino médio o ensino foi mais reforçado mais sem foco os professores ensinava bem só que a distração era grande porque os alunos acham a matéria besta.

Os aspectos os quais nomeamos "superficiais" podem ser encontrados no D8. Pois, ao evidenciar que só “agora no $3^{\circ}$ ano" procura ter mais atenção em suas aulas, revela que o seu interesse pela escrita tem uma motivação não satisfatória e uma visão simplória dessa competência. Todavia, D9 traz um apontamento das possíveis causas para essas problemáticas. Pois muitos dos alunos não conseguem interagir e trabalhar suas competências escritoras devido a ambientes como os relatados por eles: "acha a matéria besta", que de fato é um apontamento de que os assuntos não dialogam com a realidade vivida pelos educandos.

\subsection{Representações acerca do ENEM e do ensino Superior.}

Nesta subseção analisamos as representações dos alunos, o que eles dizem de sua preparação para o momento de transição para o ES; o que eles pensam do sistema público de ensino, se o mesmo fornece uma boa preparação para a principal prova de admissão no ES, o ENEM; se eles acreditam estar preparados para lidar com as práticas de letramento no ambiente profissional em que ingressarão e se as formas como foram trabalhadas as competências escritoras de fato dialogam com os modelos propostos. Para realizar essas análises, destacamos as opiniões dos alunos acerca do ENEM e em sublinhado as opiniões acerca do sistema público de ensino: 
D7: Não me sinto preparada para o ENEM, porque apesar do meu esforço, no ENEM é cobrado muitos conteúdos que não são trabalhados em sala, dando uma certa vantagem a quem estudou a vida toda em colégios particulares.

D6: Eu acho que ainda preciso melhorar bastante para o ENEM e outros vestibulares que planejo fazer [...].

D1: [...] o ENEM e bem complicado e cansativo [...]. Portanto faltado pouco tempo de preparo e so tenho conhecido regras, normas agora, não me sinto preparada para fazer uma importante prova em minha vida.

D12: As aulas de português e redação não fazem muito proveito prático da escrita, acredito que só teoria não basta. Portanto, acho que não estou preparada para uma redação nível ENEM.

D13: Ainda não e sinto qualificado para prestar um vestibular ou o ENEM, mas buscarei conhecimento além do que eu estou tendo na escola pública, pois meu objetivo é entrar em uma universidade.

Como podemos ver, a maior parte das opiniões dos alunos participantes desta pesquisa (especificamente falando 55\%) não se consideram preparados para lidar com o ENEM e os vestibulares que prestarão, o que é um número muito preocupante. $\mathrm{E}$ isso pode ser resultante da má distribuição dos cronogramas de aula contidos nas escolas no que se refere ao EM. Nas palavras de pesquisadoras da área,

O cotidiano das aulas no ensino médio nos faz perceber que uma boa percentagem das horasaulas vai para o ensino de literatura e de fundamentos da linguística e da gramática tradicional. Nesse conjunto, o ensino da leitura e da escrita é geralmente estruturado com base nos conteúdos relativos aos gêneros e aos mecanismos de textualização (KLEIMAN, CENICEROS e TINOCO, 2013 p.73).

Com isso, subentende-se que o ensino voltado para a produção textual é trabalhado de forma secundária. A grande questão é que, quando nos referimos aos parâmetros de avaliação do ENEM, o texto dissertativo/redação tem um grande peso e compõe um terço da nota. E essa importância parece não ser equiparável ao tempo dedicado ao desenvolvimento da competência escritora nas escolas durante o ensino básico, o que naturalmente torna-se um grande problema.

Neste momento, diante das afirmações expostas, tanto da parte dos alunos quanto da parte dos teóricos, fica claro a necessidade de reformulação dos currículos, pois

[...] no ensino [...] da produção de textos representativos de determinada prática social, a facilidade e a dificuldade de aprendizagem não dependem apenas da relação letra-som, ou da presença ou ausência de dígrafos, encontros consonantais e outras "dificuldades ortográficas", ou da presença de elementos coesivos mais, ou menos conhecidos do aluno. Dependem, sobretudo, do grau de familiaridade do aluno com os textos pertencentes aos 
gêneros mobilizados para comunicar-se em eventos que pressupõem essa prática (KLEIMAN, 2007, p.05).

Em detrimento disso, os alunos evidenciam outra questão acerca do sistema público de ensino. Segundo eles, o sistema, em alguns momentos, deixa a desejar quando o assunto é fornecer a base necessária para o ingresso no ES, como podemos notar na fala do D13: "Não e sinto qualificado para prestar um vestibular ou o ENEM, mas buscarei conbecimento além do que eu estou tendo na escola pública, [...]"; e D7: "No ENEM é cobrado muitos conteúdos que não são trabalhados em sala, dando uma certa vantagem a quem estudou a vida toda em colégios particulares".

Logo, é perceptível, para os alunos, que o sistema público de ensino não fornece a preparação necessária para as exigências do meio externo e que é preciso procurar conhecimentos "extraescolares", para que, assim, possam ingressar no ES. Notamos aqui a necessidade de um ensino pautado nos gêneros textuais, já que nesses é considerado o uso social da linguagem (DOLZ e SCHNEUWLY, 2010). E, além disso, Kleiman (2007, p.08) afirma que a prática social "não pode senão viabilizar o ensino do gênero, pois é seu conhecimento o que permite participar nos eventos de diversas instituições e realizar as atividades próprias dessas instituições com legitimidade".

Agora, no que se refere às perspectivas apresentadas pelos NEL, especificamente no modelo autônomo, em D1 a competência escritora é reduzida a aspectos como "regras e normas". Em D12, uma questão evidenciada é a falta de diálogo com o contexto em que estão envolvidos os alunos, como é relatado: "As aulas de português e redação não faz̧em muito proveito prático da escrita, acredito que só teoria não basta", o que nos remete novamente à discussão proposta pelo modelo ideológico e de letramento acadêmico, em que a tecnologia, a escrita, deve ser desenvolvida em diálogo com o contexto em que estão envolvidos os educandos.

\section{CONSIDERAÇÕES FINAIS}

O processo de alfabetização se finda após o indivíduo adquirir competência, mas o mesmo não ocorre com o letramento, pois na medida em que o indivíduo é inserido em novos contextos de letramentos descobre-se que é necessário que ele desenvolva algumas habilidades para poder lidar com essa nova ambiência, por exemplo, quando um aluno termina o ensino básico e logo entra no ensino superior, são exigidos desse níveis e práticas de letramentos diferentes, até então não trabalhados.

Esse processo ocorrerá novamente quando esse mesmo aluno, ao terminar seus estudos no nível superior, passar a exercer sua profissão. E, quando empregado, serão exigidos dele treinamentos e capacitações, que novamente lhe exigirão práticas de letramentos ainda não trabalhadas, e assim sucessivamente, não havendo limites para o letramento. Dessa forma, o letramento, como afirma Soares (2009), se posiciona de forma infinita. 
O objetivo do presente artigo foi investigar as representações de alunos do EM acerca de suas competências escritoras, levando em consideração o seu ingresso no Ensino Superior (ES). Com as representações, foi possível perceber as múltiplas dificuldades enfrentadas pelos alunos durante o processo de desenvolvimento da competência escritora, sendo notórias em todas as etapas de ensino.

Em relação às impressões acerca do EFII, os relatos apontaram que, mesmo sendo trabalhados conteúdos de LP, os alunos demonstraram despreparo no que se refere à produção textual, deixando evidente que as aulas eram focadas em conteúdos pautados em regras gramaticais. Não diferente, no EM a ênfase dada a conteúdos gramaticais permanecem, de maneira descontextualizada e estática. Inferimos que, por conta disso, os alunos consideram essa modalidade de ensino complexa e difícil ("Já o ensino médio tive várias dificuldades", D3), por conta da falta de preparação das modalidades anteriores ("infelizmente o ensino foi falho", D7).

Outro fato importante, constatado nos diários, foi a predominância do modelo de letramento dos estudos das habilidades, pois, nesse modelo, espera-se que os discentes dominem saberes de modalidade anteriores. Podemos notar nas análises que, de uma transição para outra, lacunas são expostas na construção do saber ("Eu acho que ainda preciso melhorar bastante para o ENEM", D6; “já no ensino médio o peso foi maior", D8) o que acarreta no despreparo para o ENEM ("Não me sinto preparada para o ENEM, porque apesar do meu esforço, no ENEM é cobrado muitos conteúdos que não são trabalhados em sala”, D7).

Nesse contexto, com o estudo, constatamos que é notória a mudança dada ao ensino, quando a perspectiva do ensino de língua materna é voltada para a prática social, "pois um enfoque socialmente contextualizado pode conceder ao professor autonomia no planejamento das unidades de ensino e na escolha de materiais didáticos" (KLEIMAN, p. 17).

Destarte, acreditamos ser necessária a implementação de programas de conteúdos flexíveis e que considerem a prática social da escrita, visando o desenvolvimento significativo de competências linguístico-discursivas dos sujeitos envolvidos.

\section{REFERENCIAS}

ASSOLINI, Filoména E.; TFOUNI, Leda V. Os (des)caminhos da alfabetização, do letramento e da leitura. Revista Paidéia. vol. 9 n. 17. Ribeirão Preto. Dez. de 1999. Disponível em: http: //www.scielo.br/pdf/paideia/v9n17/04.pdf

BATISTA-SANTOS. D. O. Letramento acadêmico: representações de ingressantes acerca da escrita. Revista Trama ISSN 19814674 Volume 13 - Número 28 - 2017, p. 
86 118, disponível em: http://erevista.unioeste.br/index.php/trama/article/view/15586/10969 2017

CASTRO, L. M. A. de. Escrita e letramento no Ensino Médio: uma abordagem sistêmico-funcional e de Linguística Aplicada. Rio de Janeiro, 2009. 150 p. Dissertação (Mestrado em Estudos da Linguagem). Departamento de Letras, PUC Rio.

DOLZ, Joaquim; SCHNEUWLY, Bernard. Gêneros orais e escritos na escola. Campinas, SP: Mercado de Letras, 2004. 278 p. (Tradução e organização: Roxane Rojo; Glaís Sales Cordeiro).

FIAD, Raquel Salek. A escrita na universidade. Revista da ABRALIN, v. Eletrônico, n. Especial, p. 357-369. $2^{\mathrm{a}}$ parte, 2011. Disponível em: http://revistas.ufpr.br/\%20abralin/article/viewFile/32436/20585.

KLEIMAN. A. B.; CENICEROS, R.C; TINOCO, G.A. Projetos de Letramento no Ensino Médio. In: BUZEN, Clecio e MENDONÇA, Marcia (Orgs). Múltiplas Linguagens para o Ensino Médio. São Paulo: Parábola Editorial 2013.

Letramento e suas implicações para o ensino de língua materna. Signo. Volume 32. Número 53. p. 1-25, Santa Cruz do Sul. Dez. 2007. Disponível em: https://online.unisc.br/seer/index.php/signo/article/view/242.

Trajetórias de acesso ao mundo da escrita: relevância das práticas não escolares de letramento para o letramento escolar. PERSPECTIVA. Volume. 28. Número. 2. 375-400. Florianópolis. Jul. /dez. 2010. Disponível em: https://periodicos.ufsc.br/index.php/perspectiva/article/view/2175795X.2010v28n2p $\underline{375 / 1844}$

LIBERALI, F. C. O diário como ferramenta para a reflexão crítica.

Tese (Doutorado em Lingüística Aplicada e Estudos da Linguagem) - PUC/SP. 1999.

MARCUSCHI, Beth. Escrevendo na escola para a vida. In: RANGEL, Egon de Oliveira; ROJO, Roxane. (Org.). Coleção Explorando o Ensino: Língua Portuguesa. Brasília: Ministério da Educação, Secretaria de Educação Básica, 2010.

MOITA LOPES, L. P. (Org.) Por uma Lingüística Aplicada Indisciplinar. São Paulo: Parábola Editorial, 2006. 279 p.

SOARES, Magda. Letramento: um tema em três gêneros. Belo Horizonte: Autêntica. 2009. 
Letramento e alfabetização: as muitas facetas. Revista Brasileira de Educação. Número 24. Minas Gerais: Jan/abr. 2004. Disponível em: http://www.scielo.br/pdf/rbedu/n25/n25a01.pdf.

STREET. B.V. Políticas e práticas de letramento na Inglaterra: uma perspectiva de letramentos sociais como base para uma comparação com o Brasil. Cad. Cedes. Campinas: v. 33. n. 89. p. 51-71. Jan.-abr. 2013. Disponível em: http://www.cedes.unicamp.br.

O Modelo de "letramentos acadêmicos": teoria e aplicações. Filol. Linguíst. Port. São Paulo: v. 16, n. 2, p. 477-493, jul./dez. 2014. Disponível em: http://dx.doi.org/10.11606/issn.2176-9419.v16i2p477-493

Recebido em: 05/06/2017 Aprovado em: 23/07/2017 Publicado em: 01/02/2018 